\title{
Analytical Method Development and Validation for Estimation of Ranitidine in Solid Dosage Form by UV-Spectrophotometric Method
}

\author{
SUBRATA PAUL ${ }^{1}$, LABANI BARAI ${ }^{2}$, MD. FARUK HUSEN ${ }^{3}$, SABARNI SARKER $^{4}$, \\ TARUN KUMAR PAL ${ }^{5}$, PUJA BAL ${ }^{6}$, MD. ABDUL MATIN SARKER $^{7}$, \\ SYEDA SAIMA ALAM ${ }^{8}$ and SHETA BISWAS ${ }^{9 *}$
}

\footnotetext{
'Department of Pharmacy, University of Rajshahi, Rajshahi-6205, Bangladesh.

2Department of Pharmacy, University of Asia Pacific, Dhaka-1205, Bangladesh.

${ }^{3}$ Department of Applied Chemistry and Chemical Engineering, University of Rajshahi,

Rajshahi-6205, Bangladesh.

${ }^{4}$ Department of Pharmacy, Faculty of Life and Earth Sciences, Jagannath University,

Dhaka-1100, Bangladesh.
}

${ }^{5}$ Department of Chemistry, Rajshahi University of Engineering \& Technology, Rajshahi-6204, Bangladesh.

${ }^{6}$ Department of Pharmacy, Faculty of Allied Health Science, Daffodil International University,

Dhaka-1207, Bangladesh.

${ }^{7}$ Department of Pharmacy, Jahangirnagar University, Savar, Dhaka-1342, Bangladesh.

${ }^{8}$ Department of Food Technology and Nutrition Science, Noakhali Science and Technology University,

Noakhali-3814, Bangladesh.

${ }^{9}$ Department of Biochemistry and Molecular Biology, Noakhali Science and Technology University,

Noakhali-3814, Bangladesh.

${ }^{*}$ Corresponding author E-mail: shwetabio1992@ gmail.com

http://dx.doi.org/10.13005/ojc/360621

(Received: October 28, 2020; Accepted: December 15, 2020)

ABSTRACT

Ranitidine is a histamine-2 receptor blocker and it is effective against peptic ulcer, gastroesophageal reflux disease and heart burn. The main objective of this study was to develop and validate an easy, affordable and cost-effective method for the determination of ranitidine in tablet dosage form. The development and validation study was performed under the guidance of $\mathrm{ICH}$ and USP. Results showed that the proposed validated method has good accuracy with \% RSD of 0.60 . Repeatability and intermediate precision suggested good precision whereas the value of correlation coefficient 0.9999 confirmed about the linearity of the method. The system suitability data and similarity factors were also found within the permissible range. The specificity study revealed that there was no placebo and diluent effect on the absorbance. Further, stability study of analytical solutions as well as estimation of drug content from market products were also performed.

Keywords: Ranitidine, Method Validation, UV-Spectrophotometer, Accuracy, Linearity.

This is an Open Access article licensed under a Creative Commons license: Attribution 4.0 International (CC- BY). Published by Oriental Scientific Publishing Company @ 2018 


\section{INTRODUCTION}

Ranitidine or (Z)-N-\{2-[(\{5-[(dimethylamino) methyl]furan-2-yl\}methyl)sulfanyl]ethyl\}-N'-methyl2-nitroethene-1,1-diamine (Fig. 1) was one of the earliest $\mathrm{H}_{2}$ histamine receptors antagonist approved for clinical use ${ }^{1}$. Soon after its discovery ranitidine was indicated against a variety of pathologies associated to gastric hyper-secretory conditions, for example, gastric ulcer, reflux acidity and heartburn ${ }^{2,3,4}$. In the late 1970's the water solubility of ranitidine had been improved with its salt form ranitidine hydrochloride and soon it became the world's best-selling drug ${ }^{5}$. It was among the top-selling pharmaceutical products before Food and Drugs Administration (FDA) found a carcinogenic impurity named $\mathrm{N}$-nitrosodimethylamine (NDMA) above limit in some of the products in 2019 and subsequently recalled it from the market ${ }^{6,7}$. However, FDA is still investigating on the impurity issue and once this issue is resolved, the production may or may not resume ${ }^{7}$.

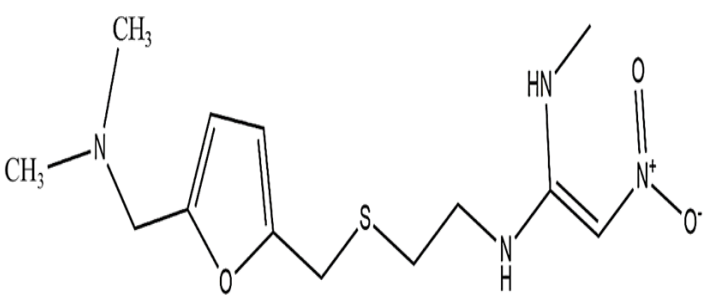

Fig. 1. Chemical structure of Ranitidine

Ranitidine hydrochloride, however, has a good physicochemical property. It has a high-water solubility and solutions are slightly acidic in nature ${ }^{8}$. There are different analytical methods that had been studied to determine the potency and impurities of ranitidine hydrochloride. Reverse phase high performance liquid chromatography (RP-HPLC) and UV-Visible spectrophotometry had been studied to quantitatively analyze the drug from solid dosage forms ${ }^{9,10,11,12}$. Among them UV-spectrophotometric method had been found as the simplest and most cost-effective method of analysis ${ }^{8,13}$. At the same time, many authors had recommended the method for routine analysis of many drugs in the commercial settings ${ }^{13,14,15}$. Stability is another issue with ranitidine hydrochloride. Previously RP-HPLC and thin layer chromatography were used to the stability study and by-products of the drug ${ }^{16,17,18}$. UV-spectrophotometric methods were also addressed in the stability studies for the drug before ${ }^{19,20}$.
Analytical method validation techniques can check the repeatability of analytical methods. The current study was designed to establish and validate a routine analytical method regarding potency and stability of ranitidine hydrochloride using UV-Visible spectrophotometry. Water was chosen as the diluent as it is suitable and cost-effective for the analysis of the drug ${ }^{21}$. The method was validated according to $\mathrm{ICH}$ and USP guidelines ${ }^{22,23}$.

\section{MATERIALS AND METHODS}

\section{Instrumentation and reagents}

UV-Visible spectrophotometer (3600 plus, Shimadzu, Japan) was used for the development and validation of the method. Sartorius analytical balance was used to measure the weight of standard and sample. Centrifugation of solution was performed by using Centrifuge EBA-20 (Sandberg). Ranitidine hydrochloride tablet and ranitidine hydrochloride USP reference standard were used for this experiment. Purified water was prepared in the laboratory.

\section{Preparation of standard 1 and standard 2}

$20.10 \mathrm{mg}$ Ranitidine hydrochloride RS (equivalent to18 $\mathrm{mg}$ of Ranitidine) was transferred into a $50 \mathrm{~mL}$ amber volumetric flask. Water was used as a diluent to obtain the volume about 30 $\mathrm{mL}$. Afterward, the solution was sonicated for 15 min and cooled down. Again, diluent (water) was applied to make the volume up to mark. Further, 1 $\mathrm{mL}$ of this solution was withdrawn to another $50 \mathrm{~mL}$ volumetric flask and the same solvent was added for attaining the final volume. The resulting solution has a concentration of $0.072 \mathrm{mg} / \mathrm{mL}$. For the preparation of standard 2, the process was repeated and the similarity factor was determined by applying the following equation:

Similarity factor $=\frac{\text { Absorbance of Standard } 1 \times \text { Weight of Standard } 2}{\text { Weight of Standard } 1 \times \text { Absorbance of Standard } 2}$

\section{Sample preparation}

20 tablets were weighed and crushed to make fine powder. Powder equivalent to 150 $\mathrm{mg}$ of ranitidine was poured into a $100 \mathrm{~mL}$ amber volumetric flask. After adding $70 \mathrm{~mL}$ diluent it was sonicated for 15 minutes. Then, the solution was cooled down and it was made up to the mark by adding diluent. The centrifugation of the solution at $3000 \mathrm{rpm}$ for $10 \mathrm{~min}$ was carried out. Further, $1 \mathrm{~mL}$ was transferred into $50 \mathrm{~mL}$ amber volumetric flask 
and the final volume was filled with diluent. Again $6 \mathrm{~mL}$ solution was poured into a $25 \mathrm{~mL}$ amber volumetric flask and the volume was filled up to the mark with water to attain the final concentration of
$0.0072 \mathrm{mg} / \mathrm{mL}$. Then the absorbance was taken with UV-Spectrophotometer at $314 \mathrm{~nm}$ and amount of ranitidine/unit dose was calculated using the following equation:

$\underline{100 \times 50 \times 1 \times \text { Std. wt }(\mathrm{mg}) \times \text { Abs. of sample } \times \text { Std. potency }(\%) \text { as it is } \times \text { Avg. wt }(\mathrm{mg}) \times 0.8958}$ Sample wt. $(\mathrm{mg}) \times 1 \times 6 \times 50 \times 50 \times$ Abs. of Std $\times 100$

\section{Validation parameters}

The parameters considered for the experiment include accuracy, precision, linearity, specificity, robustness and system suitability.

\section{Accuracy}

Accuracy was ascertained by applying of recovery studies. It was done by adding a known amount of standard above and below the label claim of pellets i.e. $80 \%, 100 \% \& 120 \%{ }^{24}$. Each level was carried out in triple times.

\section{Preparation of sample for $80 \%, 100 \%$ and $120 \%$ recovery}

Accurately weighed $133.6 \mathrm{mg}$ of ranitidine hydrochloride (equivalent to $120 \mathrm{mg}$ of ranitidine) and $177.4 \mathrm{mg}$ of placebo for $80 \%, 167 \mathrm{mg}$ of ranitidine hydrochloride (equivalent to $150 \mathrm{mg}$ of ranitidine) and $144 \mathrm{mg}$ of placebo for $100 \%$ and $200.94 \mathrm{mg}$ of ranitidine hydrochloride (equivalent to $180 \mathrm{mg}$ of ranitidine) and $110.06 \mathrm{mg}$ of placebo for $120 \%$ into a $100 \mathrm{~mL}$ volumetric flask. After that, about $70 \mathrm{~mL}$ diluent was added and sonicated for 15 minutes. Then the solution was cooled down and diluent was added for making the volume up to the mark. Furthermore, centrifugation was performed at $3000 \mathrm{rpm}$ for 20 minutes. Then, $1 \mathrm{~mL}$ of the solution was transferred into a $50 \mathrm{~mL}$ amber volumetric flask and same solvent was added to make the volume up to the mark. Again, $6 \mathrm{~mL}$ of the solution was taken into $25 \mathrm{~mL}$ amber volumetric flask and it was filled up to mark by adding water. The percent of recovery was calculated using the following equation.

Absorbance of recovery sample $\times$ Weight of standard $(\mathrm{mg}) \times$ Sample dilution Absorbance of standard $\times$ Standard dilution

\section{Precision}

In this experiment, repeatability and intermediate precision experiments was carried out for the evaluation of the precision of the developed method.

The repeatability can be elicited as a part of precision where the same experiment was performed under the same operating conditions over a short interval of time. Repeatability is also named as intraassay precision and usually elucidated by repeated analysis of a single sample (e.g. use of the analytical procedure within a laboratory on the same day using the same analyst with the same equipment) ${ }^{25}$.

Intermediate precision expresses withinlaboratory variations: different days, different analysts or equipment, etc. Usually, a different analyst repeats the repeatability of the experiment on the same sample on a different day, using different equipment if possible. In this study, for repeatability and intermediate precision, 6 repeated experiments were done and \%RSD was calculated to assess the precision of the proposed method.

\section{Linearity}

The method is valid for its desired use throughout the specified ranges which can be assured from the linearity of a test result. Incremental concentrations of samples were prepared in the working range.

\section{Preparation of linearity sample}

Linearity samples were prepared at concentrations $50 \%, 80 \%, 100 \%, 120 \%$ and $150 \%$ of the theoretical claim of a single unit ${ }^{26}$. Accurately weighed $37.5 \mathrm{mg}$ ranitidine was transferred into a 25 $\mathrm{mL}$ amber volumetric flask and diluent was added to fill the volume. Then $1 \mathrm{~mL}$ of this solution was diluted to make $50 \mathrm{~mL}$ with water. This is the mother stock solution with the concentration of $0.03 \mathrm{mg} / \mathrm{mL}$.

For $50 \%$ sample, $6 \mathrm{~mL}$ of the mother solution was taken into a $50 \mathrm{~mL}$ volumetric flask and diluent was added up to the mark. The final concentration will be $0.0036 \mathrm{mg} / \mathrm{mL}$. Again for $80 \%, 100 \%, 120 \%$ and $150 \%$ sample, $5 \mathrm{~mL}, 6 \mathrm{~mL}, 7 \mathrm{~mL}, 9 \mathrm{~mL}$ of the mother solution were taken into a $25 \mathrm{~mL}$ volumetric flask and required amount of diluent was added to 
make the volume up to mark. The concentration became $0.006 \mathrm{mg} / \mathrm{mL}, 0.0072 \mathrm{mg} / \mathrm{mL}, 0.0084 \mathrm{mg} /$ $\mathrm{mL}, 0.0108 \mathrm{mg} / \mathrm{mL}$, respectively. The absorbance's of samples were taken as per the assay method and a graph was plotted of concentration of ranitidine versus the corresponding absorbance.

\section{Robustness}

Robustness of the developed method was evaluated by the capability of a method to produce similar result upon tiny thoughtful change of different parameters of the experimental method ${ }^{27}$. The experiment was carried out in three different wavelengths $(312 \mathrm{~nm}, 314 \mathrm{~nm}$ and $316 \mathrm{~nm})$, performed with amber and colorless glassware, with and without centrifuge as well as filtration.

\section{Specificity}

The specificity can be defined as the capacity of an analytical method to estimate exactly a particular analyte in the presence of excipient or other impurities ${ }^{28}$. For the preparation of the placebo sample, accurately weighed and transferred $144 \mathrm{mg}$ of placebo into a $100 \mathrm{~mL}$ volumetric flask. Then followed the sample and standard preparation steps which was mentioned earlier. The spectrum of placebo, sample and standard solutions were taken separately for evaluating the specificity of proposed method.

\section{System suitability study}

The system suitability of a method refers to the suitability of a method for analysis and an integral part of method development. It refers to the checking of system to ensure the performance of that system. In this study, absorbance of five replicates of standard were taken to assess the system suitability of the method. It was executed before initiating the analysis ${ }^{29}$.

\section{Stability of analytical solutions}

Stability of analytical solutions (standard solution and sample solution) were determined by analyzing the solutions at $0 \mathrm{~h}$ and at $72 \mathrm{~h}$ in room temperature $\left(30^{\circ} \mathrm{C}\right)$.

\section{RESULTS AND DISCUSSION}

\section{Accuracy}

Accuracy of the analytical method was evaluated by estimation of percentage recovery of known amount of standard. The attained percentage of recovery were within the range of $99.22-100.94 \%$ with $\%$ RSD of 0.60 , which supports the compatibility of the method for routine drug analysis (Table 1).

Table 1: Accuracy study for Ranitidine

\begin{tabular}{|c|c|c|c|c|c|c|}
\hline Level & $\begin{array}{c}\text { Weight of } \\
\text { Placebo (mg) }\end{array}$ & $\begin{array}{l}\text { Amount of Std. } \\
\text { added (mg) X }\end{array}$ & $\begin{array}{l}\text { Amount Recovered } \\
(\mathrm{mg}) \mathrm{Y}\end{array}$ & $\begin{array}{c}\text { \%Recovery } \\
\left(Y / X^{*} 100\right)\end{array}$ & Mean & $\% R S D$ \\
\hline \multirow[t]{3}{*}{$80 \%$} & 177.6 & 133.6 & 133.61 & 100.01 & & \\
\hline & 177.7 & 132.8 & 133.71 & 100.68 & 99.97 & 0.73 \\
\hline & 177.5 & 134.9 & 133.84 & 99.22 & & \\
\hline \multirow[t]{3}{*}{$100 \%$} & 143.7 & 171.9 & 171.32 & 99.68 & & \\
\hline & 143.6 & 169.9 & 171.46 & 100.92 & 100.13 & 0.68 \\
\hline & 143.6 & 171.7 & 171.37 & 99.81 & & \\
\hline \multirow[t]{3}{*}{$120 \%$} & 110.2 & 213.5 & 215.51 & 100.94 & & \\
\hline & 110.2 & 215.0 & 215.43 & 100.20 & 100.60 & 0.37 \\
\hline & 111.0 & 214.0 & 215.41 & 100.66 & & \\
\hline Mean (\%recovery) & & & 100.23 & & & \\
\hline \%RSD & & & 0.60 & & & \\
\hline
\end{tabular}

Acceptance limit: Mean (\%recovery) $98.00 \%-102.00 \%$ and $\%$ RSD must be $\leq 2.00 \%$

\section{Precision}

A method is precise when under specified conditions, different measurements from the similar sample shows results in a specific and close range. ${ }^{30}$ In this experiment, intra-assay precision (repeatability) and intermediate precision were executed. Intermediate precision was performed by two different analysts on a different day, different instrument and it was found that the difference between the two results was $0.10 \%$ (acceptance Limit: $\pm 2.00 \%)$. On the other hand, \%RSD for repeatability and intermediate precision were $1.07 \%$ and $0.68 \%$, respectively which is well below the permissible range, $\leq 2.00 \%$ (Table $2 \& 3$ ). 
Table 2: Repeatability study for Ranitidine

\begin{tabular}{|c|c|c|c|c|}
\hline Determination No. & Weight of Sample (mg) & Weight of Std. (mg) & Result(mg/Unit Dose) & Assay(\%) \\
\hline 1 & 323.4 & & 154.45 & 102.97 \\
\hline 2 & 323.7 & & 154.44 & 102.96 \\
\hline 3 & 319.9 & & 156.01 & 104.01 \\
\hline 4 & 321.9 & 20.42 & 155.27 & 103.52 \\
\hline 5 & 328.7 & & 152.11 & 101.41 \\
\hline 6 & 328.9 & & 151.98 & 101.32 \\
\hline Mean of $\%$ Assay & 102.69 & & $\%$ RSD & 1.07 \\
\hline
\end{tabular}

Acceptance Limit: \%RSD must be $\leq 2.00 \%$

Table 3: Intermediate precision study for Ranitidine

\begin{tabular}{|c|c|c|c|c|c|}
\hline \multicolumn{2}{|c|}{ Analyst 1 (Day 1) } & \multirow[b]{2}{*}{ Assay (\%) } & \multirow[b]{2}{*}{ Determination No. } & \multirow{2}{*}{$\begin{array}{c}\text { Analyst } 2 \text { (Day } 2) \\
\text { Weight of sample }(\mathrm{mg})\end{array}$} & \multirow[b]{2}{*}{ Assay (\%) } \\
\hline Determination No. & Weight of sample $(\mathrm{mg})$ & & & & \\
\hline 1 & 323.4 & 102.97 & 1. & 329.7 & 102.15 \\
\hline 2 & 323.7 & 102.96 & 2. & 328.7 & 102.41 \\
\hline 3 & 319.9 & 104.01 & 3. & 323.9 & 103.98 \\
\hline 4 & 321.9 & 103.52 & 4. & 328.9 & 102.27 \\
\hline 5 & 328.7 & 101.41 & 5. & 327.7 & 102.63 \\
\hline 6 & 328.9 & 101.32 & 6. & 329.5 & 102.11 \\
\hline Mean & & 102.69 & & & 102.59 \\
\hline$\% R S D$ & & 1.07 & & & 0.68 \\
\hline
\end{tabular}

Difference between two results: $0.10 \%$, Acceptance Limit: $\pm 2.00 \%$ difference between two results and $\%$ RSD must be $\leq 2.00 \%$

\section{Linearity}

If concentration measurements over a different set of independent variables, such as absorbance, result in a proportional relationship, the method is said to be linear. The linearity of ranitidine was estimated in the concentration range of $0.0036 \mathrm{mg} / \mathrm{mL}$ to $0.0108 \mathrm{mg} / \mathrm{mL}$. The line must be linear within the studied concentration range and the correlation coefficient of 0.9999 is generally regarded as acceptable ${ }^{31}$. Regression analysis deduced a linear equation: $y=46$. $295 x-0.0014\left(r^{2}=0.9999\right)$, indicating a linear relationship between the concentration of analyte and absorbance (Figure 2).

Table 4: Linearity study for Ranitidine

\begin{tabular}{ccc}
\hline Determination No. & $\begin{array}{c}\text { Concentration } \\
(\mathrm{mg} / \mathrm{ml})(\mathrm{X} \text { Axis })\end{array}$ & $\begin{array}{c}\text { Absorbance } \\
(\mathrm{Y} \text { Axis })\end{array}$ \\
\hline 1 & 0.0036 & 0.16302 \\
2 & 0.0059 & 0.26962 \\
3 & 0.0071 & 0.32835 \\
4 & 0.0083 & 0.38574 \\
5 & 0.0108 & 0.49754 \\
\hline
\end{tabular}

Correlation of coefficient $(\mathrm{r} 2)=0.9999$; Acceptance Limit: The value of $r^{2}$ must be $>0.999$

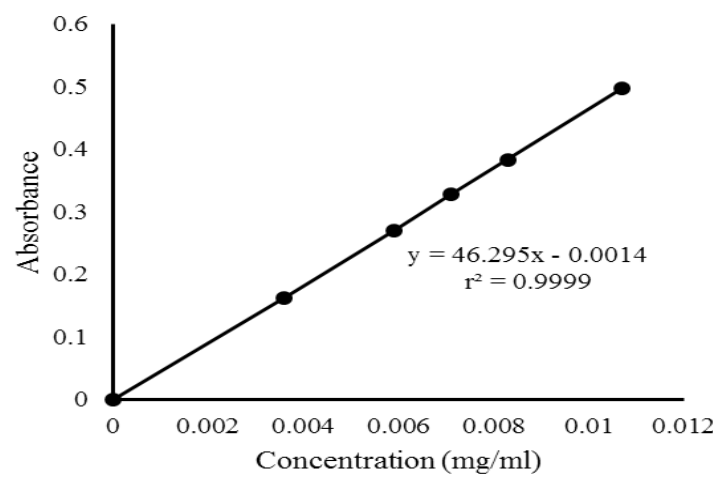

Fig. 2. Linearity study of Ranitidine

\section{Robustness}

Robustness study showed that a minor change of method parameters doesn't influence much on the final results (Table 5). Small changes in parameter did not affect much on the percentage of drug content and in every case the percentage RSD was found within the permissible range which support robustness of the proposed method.

\section{Specificity}

The specificity of the method was evaluated by comparing the absorbance of diluent plus placebo solution, standard solution, and sample solution. Fig. 3 demonstrated that there was no effect of diluent and placebo solution. 
Table 5: Robustness study

\begin{tabular}{lccc}
\hline Parameters & \% Drug Content & \%Target & \% RSD \\
\hline Filtration: Yes & 97.06 & 100 & 1.49 \\
Filtration: No & 99.14 & 100 & \\
Centrifuge: Yes & 97.88 & 100 & 1.23 \\
Centrifuge: No & 99.61 & 100 & \\
Wavelength 312 nm & 98.83 & 100 & 0.34 \\
Wavelength 314 nm & 99.25 & 100 & \\
Wavelength 316 nm & 98.58 & 100 & \\
Amber Glassware & 100.61 & 100 & 1.68 \\
Colourless Glassware & 98.24 & 100 & \\
\hline
\end{tabular}

Acceptance Limit: \%RSD must be $\leq 2.00 \%$

\section{System suitability study}

The system suitability was evaluated by five replicate analyses of the ranitidine reference standard at a $100 \%$ level. The results of system suitability are represented in Table 6 . Both \%RSD and similarity factors for day 1 and day 2 were found within the acceptance limit.

\section{Stability of analytical solutions}

Ranitidine reference standard and sample solutions showed good stability in diluent (water) over a period of $72 \mathrm{~h}$ when stored at room temperature. Fig. 4 suggested no spectrophotometric degradation during this period. The spectrum of analytical solutions after $72 \mathrm{~h}$ was almost similar to

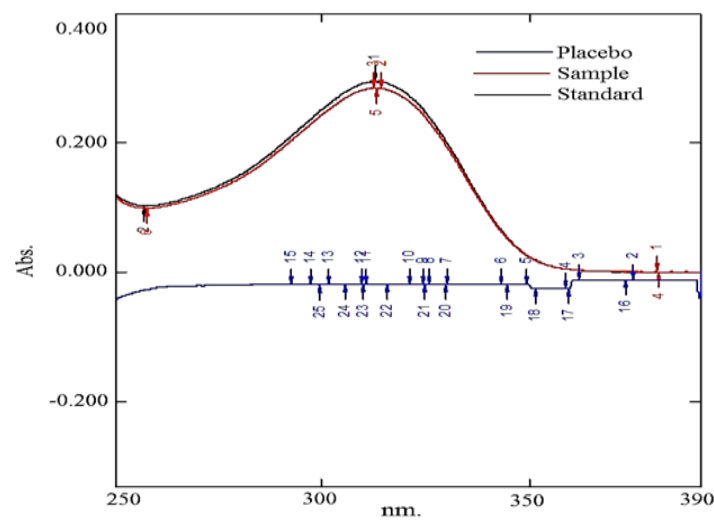

Fig. 3. UV-absorption spectra of standard, sample and placebo the spectrum of freshly prepared solutions.

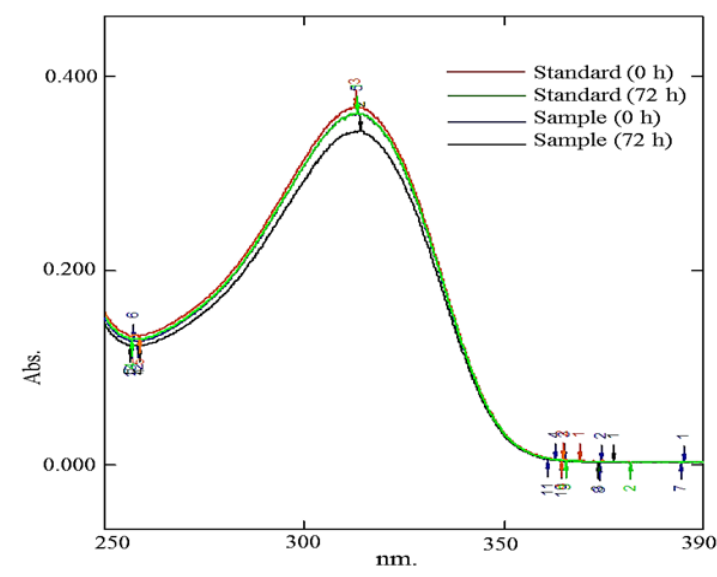

Fig.4. Stability of analytical solutions

Table 6: System suitability study for Ranitidine

\begin{tabular}{|c|c|c|c|c|c|}
\hline \multicolumn{2}{|l|}{ Day- 1} & \multicolumn{3}{|c|}{ Day- 2} & \multirow[b]{2}{*}{ Similarity Facto } \\
\hline Determination No. & Absorbance & Similarity Factor & Determination No. & Absorbance & \\
\hline 1 & 0.34365 & & 1 & 0.34844 & \\
\hline 2 & 0.34397 & & 2 & 0.34916 & \\
\hline 3 & 0.34499 & 0.99 & 3 & 0.34871 & 1.01 \\
\hline 4 & 0.34414 & & 4 & 0.34876 & \\
\hline \multirow[t]{2}{*}{5} & 0.34368 & & 5 & 0.34791 & \\
\hline & \% RSD 0.15 & & & \% RSD 0.13 & \\
\hline
\end{tabular}

Acceptance limit: \% RSD $\leq 2.00 \%$, Similarity Factor: 0.98-1.02

\section{Assay of commercial dosage form}

Five different brands of ranitidine tablets were randomly purchased from medicine shop of Dhaka, Bangladesh. Then percentage content of ranitidine was determined by the proposed validated spectrophotometric method. Each experiment was performed in three replicates and are summarized in Table 7.
Table 7: Estimation of Ranitidine in commercial formulations

\begin{tabular}{cccc}
\hline Brand & $\begin{array}{c}\text { Labeled amount } \\
(\mathrm{mg})\end{array}$ & $\begin{array}{c}\text { Obtained amount } \\
(\mathrm{mg})\end{array}$ & \%Drug content \\
\hline SP-1 & 150 & 150.39 & 100.26 \\
SP-2 & 150 & 148.64 & 99.09 \\
SP-3 & 150 & 147.36 & 98.24 \\
SP-4 & 150 & 153.17 & 102.11 \\
SP-5 & 150 & 151.23 & 100.82 \\
\hline
\end{tabular}




\section{CONCLUSION}

The experiment propounds a new and simpler pattern of analytical method validation of ranitidine in tablet dosage forms with UV-Visible spectrophotometer. The use of water as a diluent made it cost-effective too. The method is precise and reproducible as well as the percent recovery data was in agreement with the claims in the label. From the concentration ranging from $0.0036 \mathrm{mg} / \mathrm{mL}$ to $0.0108 \mathrm{mg} / \mathrm{mL}$, the results were found having linear relationship. It is also found robust, that is, small variations of parameters did not affect the method. It is specific and selective, free of any placebo effect. The analytical solutions also found stable for 72 hours. Further, this propounded method were able to determine the content of ranitidine in five different brands of ranitidine tablets. As the proposed method is easy, rapid, affordable with satisfied accuracy, precision, linearity, specificity, robustness and reproducibility, it can be recommended for the determination of the amount of ranitidine in tablet dosage form.

\section{ACKNOWLEDGEMENT}

The first author, Subrata Paul is grateful to Square Pharmaceuticals Limited, Bangladesh for supplying the Ranitidine (sample) and Ranitidine (standard).

\section{Conflict of interest}

No conflict of interest to declare.

\section{REFERENCES}

1. Ganellin, C. R. Analogue-Based Drug Discovery., 2006, 71-80.

2. Gaginella, T. S.; Bauman, J. H. Drug. Intell. Clin. Pharm., 1983, 17(12), 873-885.

3. Brogden, R.N.; Heel, R.C.; Speight, T. M.; Avery, G. S. Drugs., 1978, 15(2), 93-131.

4. Zeldis, J. B.; Friedman, L. S.; Isselbacher, K. J. N. Engl. J. Med., 1983, 309(22), 1368-1373.

5. Li J. J. Oxford University Press., 2014.

6. Aschenbrenner, D. S. Am. J. Nurs., 2020, 120(8), 23.

7. Wagner, J. A.; Colombo, J. M. Clin. Transl. Sci., 2020.

8. Shah, R. B.; Hullahalli, P. R.; Tawakkul, M. A.; Faustino, P. J.; Nguyenpho, A.; Khan, M. A. Clin. Res. Regul. Aff., 2006, 23(1), 35-51.

9. Haque, A.; Shahriar, M.; Parvin, M. N.; Islam, S. M. Asian. J. Pharm., 2011, 1(3), 59-63.

10. Beaulieux, N.; Lacroix, P. M.; Sears, R. W.; Lovering, E. G. J. Pharm. Sci., 1988, 77(10), 889-892.

11. US pharmacopoeial convention. United States Pharmacopeia. Asian edition, US pharmacopoeial convention, Inc.: US., 2009.

12. Charde, M.S.;Walode, S.G.;Tajne, M.R.; Kasture, A. V. Indian J. Pharm. Sci., 2006, 68(5), 658-659.

13. Haque, T.; Talukder, M. M. U.; Laila, S.; Fatema, K.; Kabir, A. K. L. S. J. Pharm., 2008, 1(1), 18-24.

14. Paul, S.; Mia, M.A.K.; Sarker, S.; Biswas, S.; Bal, P.; Dey, T.R.; Pal, T.K. Orient. J. Chem., 2020, 36(5), 908-914.

15. Behera, S.; Ghanty, S.; Ahmad, F.; Santra, S.; Banerjee, S. J. Anal. Bioanal. Tech., 2012, 3(6), 151-7.

16. Vehabovic, M.; Hadzovic, S.; Stambolic, F.; Hadzic, A.; Vranjes, E.; Haracic, E. Int. J.
Pharm., 2003, 256(1-2), 109-115.

17. Evans, M. B.; Haywood, P. A.; Johnson, D.; Martin-Smith, M.; Munro, G.; Wahlich, J. C. J. Pharm. Biomed.,1989, 7(1), 1-22.

18. Wong, C. F.; Peh, K. K.; Yuen, K. H. J. Chromatogr. B Biomed. Appl., 1998, 718(1), 205-210.

19. Kelani, K. M.; Aziz, A. M.; Hegazy, M. A.; Abdel Fattah, L. Anal. Lett., 2002, 35(6), 1055-1073.

20. Orsine, E. M. D. A.; Martins, J. L. S. Anal. Lett., 1993, 26(9), 1933-1941.

21. Desta, K.; Amare, M. Chem. Int., 2017, 3(3), 288-295.

22. $\mathrm{ICH}$ Guideline; Validation of Analytical Procedures: Text and Methodology. Topic Q 2 (R1). (2005). Geneva, Switzerland.

23. United States Pharmacopoeia United States Pharmacopeial Convention, 26 ${ }^{\text {th }}$ Edition, Rockville, MD., 2003.

24. Dhanwate, S.S.; Pachauri, A.D.; Ghode, P.D.; Khandelwal, K.R. J. Pharm. Sci. \& Res., 2019, 11(8), 2886-2890.

25. Haque, M.A.; Naznin, A.; Kabir, A.H.; Hossain, M.K.; Islam, S.A. Dhaka Univ. J. Pharm., 2010, 9(2), 131-138.

26. Chandran, S.; Singh, R.S. Pharmazie., 2007, 62(1), 4-14.

27. Naseef, H.; Moqadi, R.; Qurt, M. J. Anal. Methods. Chem., 2018, 190, 2510.

28. Batrawi, N.; Naseef, H.; Al-Rimawi, F. J. Anal. Methods. Chem., 2017, 15,29280.

29. Sharma, S.; Goyal, S.; Chauhan, K. Int. J. App. Pharm., 2018, 10(6), 8-15.

30. Fda. Guidance for Industry: Validation of Analytical Procedures: Definition and terminology., 2010.

31. Miller, J.N. Analyst., 1991, 116(1), 3-14. 